his story in a relentless deadpan, which is at first alienating but then gets under the skin. As the story develops, your sympathy for the two men grows, as their own does for each other. One of the things they agree on, for example, is the deplorability of "novels that wandered off into lying fables because the author tied his fake inventions to the names of real historical personages".

Kehlmann, then, does a good job of captur- ing the strangeness and comedy of science, as well as the powerful sense of futility that can afflict researchers from time to time. But he doesn't get near to explaining why, despite its oddness, science provides such powerful and beautiful answers to our questions, or why mathematics has such an uncanny power to provide these answers. Nor do we get any idea why a few people, such as Gauss, have mathematical abilities that seem supernatural to the rest of us, or why others, such as Humboldt, are willing to give up their fortunes, comforts and sometimes lives to see, and measure, what's over the horizon. Quite right too, I'm tempted to think - where would the fun be in knowing that?

John Whitfield lives in London and is the author of In the Beat of a Heart: Life, Energy, and the Unity of Nature (Joseph Henry Press). www.inthebeatofaheart.com

\title{
The molecular landscape
}

\section{Lucia Covi uses modern microscopy to highlight the world at the nanoscale.}

\begin{abstract}
Martin Kemp
"We are 'connoisseurs of chaos', patterners. So we look for resemblances to things in our experience... The gold tip is a digital Tower of Babel, or a wedding cake. And a fractal set, and the electron microscope image I once saw of a small worm's mouth."

So says Roald Hoffmann, winner of the 1981 Nobel Prize in Chemistry, in his introduction to Lucia Covi's book Blow Up: Images from the Nanoworld (Damiani Editore, $€ 26$; www.damianieditore.it). Hoffmann's brief essay should be compulsory reading for anyone involved with machine-generated images in either science or art.

Covi is a Milanese photographer who has worked with Elisa Molinari and her colleagues at the Italian National Research Center on nanoStructures and bioSystems at Surfaces in Modena. Together they have made extraordinary structures visible at the scale of millionths of millimetres. Covi's book was published to mark an exhibition previewed at the 2006 Genoa Science Festival and now on show in Modena (www.s3.infm.it/blowup). It also stands on its own as a visually and intellectually stimulating panorama of images from the strange yet somehow familiar nanolandscapes of modern microscopy.

Covi has turned scientific data into 'photographs' to magnify their visual impact. This often involves limiting the propensity
\end{abstract} of scientists to render their computer images in garish colours, a cacophony of metallic hues and tones. To make the images appear convincing and highlight their beauty, all the visual effects need to be internally consistent. As Hoffmann declares: "Differences in surface texture, in smoothness and roughness matter. They are compared in our brain with memories of tangible objects." Internal visual consistency is an incredibly subtle matter.

The image of the gold tip (shown here), specifically mentioned by Hoffmann and used on the cover of the book, was captured by a scanning electron microscope focused on the tip of a probe used in scanning near- field optical microscopy - one microscope in effect scrutinizing another.

Just like Robert Hooke, when he described the wondrous little 'engines' and landscapes he witnessed when compiling his Micrographia in 1665 , we automatically draw perceptual parallels with familiar objects when we see new structures.
At this scale - as perhaps at every level of the structural organization of the material world - the basic building blocks aggregate and form into morphologies that are recognizably regular yet irreducibly individual and unpredictable.

My one quarrel with Hoffmann is when he declares: "No one is born with a feeling for

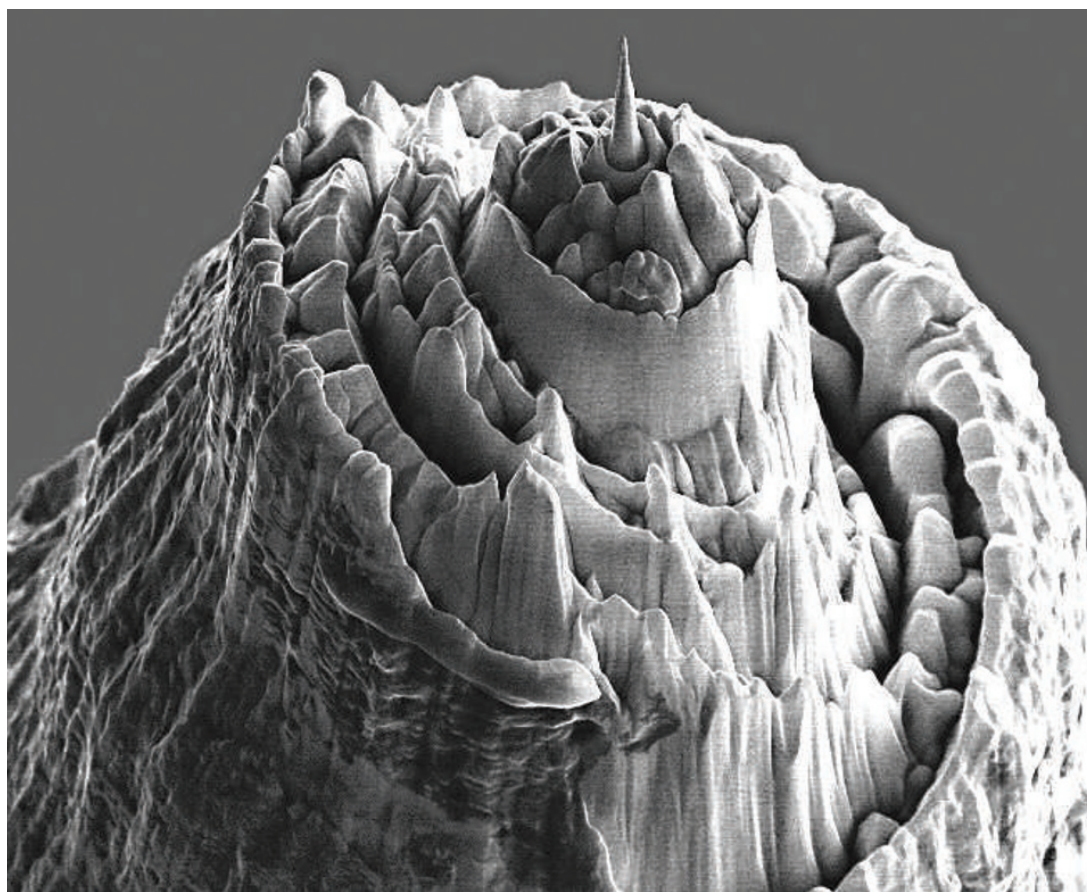

Making a point: a gold tip used in microscopy resembles Brueghel's Tower of Babel.

Now, in this age of fractal landscapes in science fiction and animated films, my first thought when seeing the gold tip is of a fantasy castle constructed on a conical mountain-top. Or, to pick up Hoffmann's more erudite, historical parallel, the Tower of Babel as characterized in Pieter Brueghel's amazing sixteenth-century painting.

The gold tip is an artefact of the nanosculptor's craft. It was sculpted by milling with a focused ion beam, a top-down process. Other images in the book show structures that have self-assembled spontaneously, in a bottom-up manner. harmonious arrangement." My conviction is that our systems of perception and cognition are profoundly endowed with an innate propensity for discerning levels of order and disorder, which I have termed 'structural intuition'. The images in Covi's book present a veritable field day for the exercising of this propensity - whether we think it is taught or innate, or a compound of both.

Martin Kemp is professor of the history of art at the University of Oxford, Oxford OX1 1PT, UK. His new book, Seen | Unseen, is published by Oxford University Press. 